\title{
Lasting Adaptations in Social Behavior Produced by Social Disruption and Inhibition of Adult Neurogenesis
}

\author{
Maya Opendak, ${ }^{1}$ Lily Offit, ${ }^{1,2}$ Patrick Monari, ${ }^{1,2}$ Timothy J. Schoenfeld, ${ }^{3}$ Anup N. Sonti, ${ }^{3}$-Heather A. Cameron, ${ }^{3}$ \\ and Elizabeth Gould ${ }^{1,2}$ \\ ${ }^{1}$ Princeton Neuroscience Institute and ${ }^{2}$ Department of Psychology, Princeton University, Princeton, New Jersey 08540, and ${ }^{3}$ National Institute of Mental \\ Health, National Institutes of Health, Bethesda, Maryland 20892
}

Research on social instability has focused on its detrimental consequences, but most people are resilient and respond by invoking various coping strategies. To investigate cellular processes underlying such strategies, a dominance hierarchy of rats was formed and then destabilized. Regardless of social position, rats from disrupted hierarchies had fewer new neurons in the hippocampus compared with rats from control cages and those from stable hierarchies. Social disruption produced a preference for familiar over novel conspecifics, a change that did not involve global memory impairments or increased anxiety. Using the neuropeptide oxytocin as a tool to increase neurogenesis in the hippocampus of disrupted rats restored preference for novel conspecifics to predisruption levels. Conversely, reducing the number of new neurons by limited inhibition of adult neurogenesis in naive transgenic GFAP-thymidine kinase rats resulted in social behavior similar to disrupted rats. Together, these results provide novel mechanistic evidence that social disruption shapes behavior in a potentially adaptive way, possibly by reducing adult neurogenesis in the hippocampus.

Key words: dominance hierarchy; GFAP-TK transgenic rats; hippocampus; neurogenesis; oxytocin; social behavior

\section{Significance Statement}

To investigate cellular processes underlying adaptation to social instability, a dominance hierarchy of rats was formed and then destabilized. Regardless of social position, rats from disrupted hierarchies had fewer new neurons in the hippocampus compared with rats from control cages and those from stable hierarchies. Unexpectedly, these changes were accompanied by changes in social strategies without evidence of impairments in cognition or anxiety regulation. Restoring adult neurogenesis in disrupted rats using oxytocin and conditionally suppressing the production of new neurons in socially naive GFAP-thymidine kinase rats showed that loss of 6-week-old neurons may be responsible for adaptive changes in social behavior.

\section{Introduction}

Social instability is associated with an increased risk of mental illness, including depression and anxiety disorders in humans (Vives et al., 2011; Bossarte et al., 2013). Although instability can be a health risk, social disruption is a normal part of life, because peer groups and interpersonal relationships change with age and circumstances. Despite acute risks to mental health, studies show

Received Dec. 11, 2015; revised May 13, 2016; accepted May 16, 2016.

Author contributions: M.O., A.S., H.A.C., and E.G. designed research; M.O., L.O., P.M., T.S., and A.S. performed research;H.A.C. contributed unpublished reagents/analytictools; M.O., L.O.,P.M., A.S., and E.G. analyzed data;M.O., P.M., T.S., H.A.C., and E.G. wrote the paper.

This work was supported in part by the Intramural Program of the National Institutes of Health/National Institute of Mental Health (Grant ZIAMH002784 to H.A.C.).

Correspondence should be addressed to Elizabeth Gould, Department of Psychology, Princeton Neuroscience Institute, Princeton University, Princeton, NJ 08540. E-mail: goulde@princeton.edu.

Maya Opendak's current address: Emotional Brain Institute, Nathan Kline Institute, Orangeburg, NY and Child Study Center, Child \& Adolescent Psychiatry, New York University School of Medicine, New York, NY.

DOI:10.1523/JNEUROSCI.4435-15.2016

Copyright $\odot 2016$ the authors $\quad 0270-6474 / 16 / 367027-12 \$ 15.00 / 0$ that humans display long-term resilience and use various coping strategies even in response to chronic instability (Khoshaba and Maddi, 1999; Gunnar et al., 2009; Cutuli et al., 2013). Similar to humans, rodents display negative consequences to short-term social disruption but often recover completely unless social interactions are predominantly aversive, as in the case of chronic social defeat (McCormick and Green, 2013; Bourke et al., 2014). Nonetheless, the vast majority of studies on social instability in rodents have been designed to ensure negative outcomes, with relatively little research focused on adaptation and its cellular mechanisms (McCormick et al., 2012, 2015; Branchi et al., 2013a,b).

In the wild, rats form social hierarchies in which a period of intense fighting is followed by stabilization when the most aggressive rat emerges as the dominant (Krames et al., 1969). This arrangement coincides with a reduction in fighting, because nondominant members of the group adjust their behavior in response to the dominant. Although hierarchy stability can be lasting, destabilization is common, occurring as a result of death, aging, or illness of a dominant 
rat, a rogue rat joining the group, or a change in habitat conditions (Barnett, 1958). Because such behavior is difficult to study in the wild, the visible burrow system (VBS) was designed to mimic seminaturalistic social living for rats in a laboratory setting (Blanchard et al., 1991, 1995, 2013). Dominant rats in a stable hierarchy in the VBS exhibit a higher rate of adult neurogenesis in the hippocampus compared with subordinate rats (Kozorovitskiy and Gould, 2004), but no previous studies have explored the effects of hierarchy destabilization on the brain and behavior. Because adult neurogenesis in the hippocampus has been linked to a variety of functions, including anxiety/stress regulation and cognition (Dupret et al., 2008; Snyder et al., 2011; Opendak and Gould, 2015), it is likely that changes related to dominance hierarchy destabilization could have important behavioral consequences. To investigate this further, we explored the effects of living in stable and unstable hierarchies on new neuron production in the hippocampus and on behaviors that have been associated with this brain region. We found that differences between dominants and subordinates in adult neurogenesis were eliminated when the hierarchy was disrupted. We further found that new neuron production in the hippocampus was consistently lower after social disruption. Despite suppressed neurogenesis, rats from disrupted hierarchies displayed reduced anxiety-like behavior without global cognitive deficits. These rats also show a marked change in social behavior. Although control rats and rats from stable hierarchies prefer novel over familiar rats while resting, rats from disrupted hierarchies exhibit the converse preference of familiar over novel rats.

Next, we used two approaches to investigate whether these behavioral effects are linked to a reduction in the number of new neurons. We used the neuropeptide oxytocin to stimulate adult neurogenesis (Leuner et al., 2012) immediately after social disruption and tested behavior several weeks later, at a time when new neurons would have incorporated into the circuitry. We found that this manipulation had no effect on anxiety-like behavior but prevented the social preference for familiar conspecifics. Then, we used transgenic conditional neurogenesis knock-out [GFAP-thymidine kinase (TK)] rats to reduce new neuron number in rats (Snyder et al., 2016) without social disruption experience and found that these rats had control levels of anxiety-like behavior but social resting preference for familiar conspecifics. Our results show that social disruption produces a resilient phenotype, with reduced anxiety, generally preserved cognition, and a change in social preference and that suppressed neurogenesis in the hippocampus may play a role in this latter outcome.

\section{Materials and Methods}

\section{Animals}

All animal procedures were approved by the Princeton University Institutional Animal Care and Use Committee and conformed to guidelines of the National Research Council. Adult male Sprague Dawley rats (6-8 weeks of age, Taconic Farms) were housed on a $12 \mathrm{~h}$ light/dark reverse light cycle with lights off at 7:00 A.M. and ad libitum access to food and water. Adult female Sprague Dawley rats (Taconic) were used as stimulus animals in the VBS studies (see below). Sprague Dawley rats were used because this relatively docile strain can be group-housed in a VBS without risks of injurious fighting. For neurogenesis knock-out experiments in rats not subjected to VBS living, adult male Long-Evans GFAP-TK transgenic rats were used (Snyder et al., 2016). Controls for behavioral studies using neurogenesis knock-out rats were GFAP-TK rats not treated with the drug that activates the transgene [valganciclovir (GCV)]. Controls for the corticosterone (CORT) study using neurogenesis knock-out rats were Long-Evans wild-type rats.

\section{Animal housing}

Sprague Dawley rats were housed in groups of four males and two females in a modified version of the VBS (Kozorovitskiy and Gould, 2004; Fig. 1B). The VBS was made from wood and Plexiglas, with opaque wood side panels and transparent Plexiglas tunnels and chambers. The VBS consisted of an open field area $(36 \times 36$ inches), covered by bedding material lit by an overhead fluorescent light during the light phase and a red light bulb during the dark phase of the reverse $12 \mathrm{~h}$ light/dark cycle. Red light illumination allowed for videotaping in the dark to determine dominance status of the rats. Standard laboratory rat cages were used for controls and the post-VBS housing portions of the experiments. GFAP-TK rats were also housed in standard cages.

\section{Social disruption manipulation}

Rats were marked with black dye in different patterns for identification on videotapes before placement in the VBS. To determine which rat emerged as the dominant by the end of $3 \mathrm{~d}$, each colony of four males was videotaped for $10 \mathrm{~h}$ during the dark phase for each day in the VBS. Three days is sufficient time for establishing dominance hierarchies among male Sprague Dawley rats (Kozorovitskiy and Gould, 2004). In each cohort, a dominant rat was selected based on the quantity of offensive relative to defensive behaviors. Behavioral measurements were sampled hourly from videotapes, in 10-min-long intervals, adding up to the total of 300 min per colony. Male-to-male dyadic interactions involving chasing, lateral attacks, boxing, and fighting on ramps were scored as instances of offensive behavior; fleeing the open field and underside exposure were scored as defensive actions (Blanchard et al., 1995; Kozorovitskiy and Gould, 2004). For each male, the number of defensive acts was subtracted from the number of offensive acts over the entire $300 \mathrm{~min}$ sampling period, yielding one score. The rat with the highest score was designated as the dominant, and the other three males in the colony were considered subordinate. On day 4, the dominant rats were switched between two VBS communities. After the disruption, rats were videotaped during the dark phase for 3 more days to determine whether stable hierarchies re-emerged among the new configurations. Behavior during the active period was sampled for $300 \mathrm{~min}$ as described above, and each rat's aggressive and defensive actions were tallied to determine postswitch changes in aggression and hierarchy dynamics. On day 7, rats were returned to individual home cages until perfusion. Individual housing was used after the social disruption paradigm to prevent effects of additional social experience after group living in the VBS.

For comparison purposes with this study, additional cohorts of rats lived in standard laboratory cages (control) or in nondisrupted hierarchies (stable). Rats living in stable hierarchies remained in their initial cohorts for $6 \mathrm{~d}$ before being returned to individual housing. The rats living in standard cages were housed in pairs for $3 \mathrm{~d}$ with ad libitum access to food and water. On day 4 , one rat from each pair was switched with another from a separate cage to determine whether a change in cage mate was sufficient to induce social disruption effects. Rats continued to live in these configurations for $3 \mathrm{~d}$ and then were moved to individual housing, as described above.

Rats from all groups (disrupted VBS, stable VBS, cage control) were perfused at either a 2 or 6 week time point relative to the start of the experiment. The first time point was used to examine effects on immature neuron production, whereas the second time point was selected because it is sufficient for neurons generated during social experience to become functionally integrated into the existing hippocampal circuitry and affect performance on hippocampus-dependent tasks (Snyder et al., 2009).

\section{Drug treatments and perfusions}

Rats received equimolar injections of thymidine analogs iododeoxyuridine (IdU; $57.5 \mathrm{mg} / \mathrm{kg}$, i.p.; MP Biomedicals) on day 3 and chlorodeoxyuridine (CldU; $42.5 \mathrm{mg} / \mathrm{kg}$, i.p.; Sigma-Aldrich) on day 6. Selective BrdU antibody sensitivities for IdU versus CldU allow for distinct assays of cell proliferation before and after our manipulation (Vega and Peterson, 2005; Leuner et al., 2009).

Separate groups of rats living in disrupted hierarchies were treated with the neuropeptide oxytocin $(1 \mathrm{mg} / \mathrm{kg}$, i.p.; Bachem) for $7 \mathrm{~d}$ after 
A

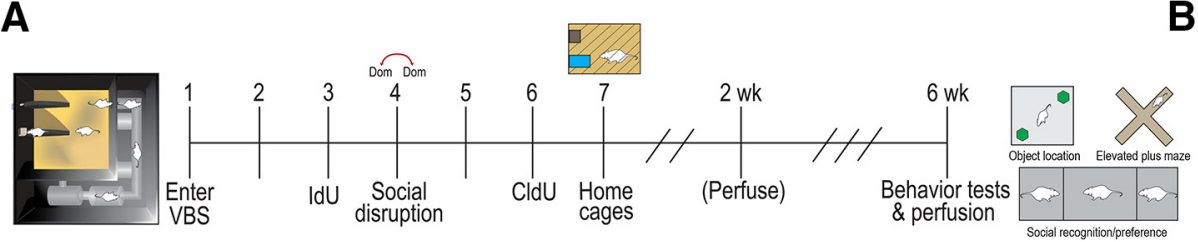

B

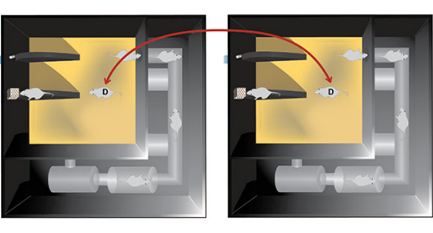

C

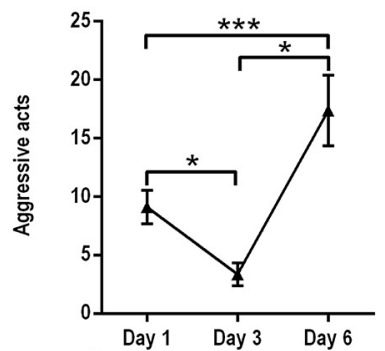

G

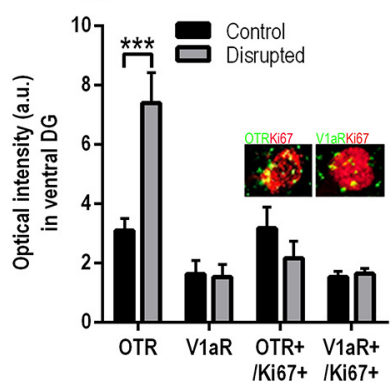

D

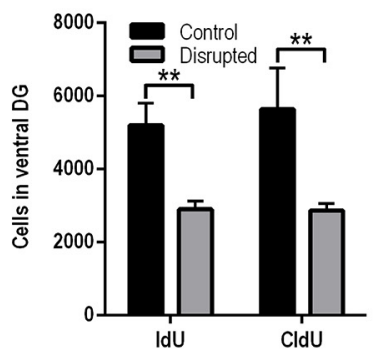

H

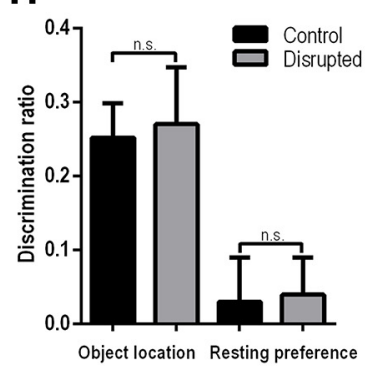

E

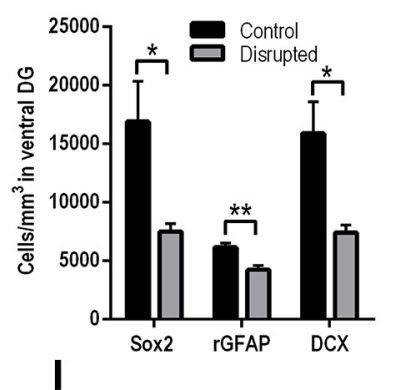

I

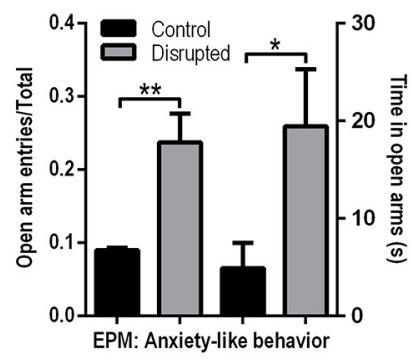

F

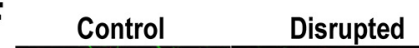

Figure 1. Social disruption suppresses adult neurogenesis without impairing performance on hippocampus-dependent tasks. $A$, Timeline for hierarchy, neuronal birthdating and behavioral testing in rats living in a dominance hierarchy. $\boldsymbol{B}$, Schematic of dominant (D) switch on day 4 in a disrupted hierarchy. $\boldsymbol{C}$, Individual aggressive acts decrease by day 3 in a VBS, but disrupting a hierarchy by switching dominants on day 4 produces an increase in aggression. $\boldsymbol{D}, \mathrm{IdU}^{+}$and $\mathrm{CIdU}^{+}$cells in the ventral DG are decreased in number in rats from a disrupted hierarchy. $\boldsymbol{E}$, Sox2 ${ }^{+}$, radial GFAP ${ }^{+}$ $\left(\mathrm{rGFAP}^{+}\right)$, and $\mathrm{DCX}{ }^{+}$cells in the ventral $\mathrm{DG}$ are decreased in number in rats from a disrupted hierarchy. $F$, First row, Representative images of Sox2/GFAP-labeled radial glia-like progenitor cells in DG. Red, Sox2; green, GFAP. Second row, Representative images of DCX-labeled immature neurons in DG, indicated by arrows. Red, DCX; blue, Hoechst 33342. Third row, Representative images of IdU-labeled cells in DG with cresyl violet counterstain, indicated by arrows. Fourth row, Representative images of OTR and V1aR staining patterns in the hypothalamus. $G, 0 T R$ staining, but not V1aR staining, is increased in the ventral DG in rats from a disrupted hierarchy, but no changes were observed in the number of cells colabeled for Ki67 and 0TR or Ki67 and V1aR. Inset, Representative images of Ki67-stained progenitor cells colabeled with OTR or V1aR. $\boldsymbol{H}$, There were no differences in rats' object location memory performance, because both groups investigate an object in a novel location more than an object in a familiar location. Neither group showed a preference for resting near objects located in novel or familiar locations. Bars indicate mean relative recognition and resting preference expressed as a discrimination ratio [discrimination ratio $=$ (time spent near novel object - time spent near familiar object)/total time]. Values $>0$ indicate a preference for the novel object. $I$, Rats from disrupted hierarchy spent more time in the open arms of an elevated plus maze than controls, in terms of both absolute time and proportion of entries in the open arms. Bars indicate mean + SEM. ${ }^{*} p<0.05,{ }^{* *} p<0.01,{ }^{* * *} p<0.001$. n.s., No significant difference; VMH, ventromedial hypothalamus; LH, lateral hypothalamus; SCh, suprachiasmatic nucleus; $3 \mathrm{~V}$, third ventricle; MPO, medial preoptic area; AHy, anterior hypothalamic area.

return to individual housing at a dose shown to increase adult neurogenesis in the hippocampus (Leuner et al., 2012). Rats were either perfused at 1 week after the last oxytocin injection (2 weeks after social disruption) to assess the effects of oxytocin treatment on immature neurons or remained in individual housing until behavioral testing at a 6 week time point to allow for adult-born neurons to affect performance on hippocampus-dependent tasks.

For GFAP-TK experiments, beginning at 8 weeks of age, pair-housed TK rats were treated with $4.0 \mathrm{mg}$ of GCV (Valcyte; Roche) per half-gram of peanut butter. Previous studies have shown that oral administration is an effective way to deliver this drug (Snyder et al., 2011;2016). Rats were fed the peanut butter treat twice weekly for 2 weeks and received injections of BrdU (200 mg/kg, i.p.; Roche) after the second drug treatment each week. The rats remained pair-housed and were perfused 6 weeks after the first GCV treatment. Control TK rats received peanut butter without GCV.

\section{Hormone assays}

Additional cohorts of rats were used to examine the effects of social disruption on basal levels of CORT and testosterone. These rats lived in either cage control or disrupted VBS conditions and received sham injections on day 3 , and trunk blood was rapidly collected within 3 min of capture on day 6 at lights on. After the blood was centrifuged, plasma was collected, and circulating CORT and testosterone (in nanograms per milliliter) were measured using a radioimmunoassay (Coat-A-Count; Siemens). Assay sensitivity was $98.5 \%$. To determine whether GFAP-TK rats with inhibited neurogenesis have altered baseline stress hormone levels, additional pair-housed GFAP-TK rats and wild-type controls were treated with GCV as described above. Blood was collected from the tail vein within 3 min of cage opening, and the serum was analyzed for CORT as described above.

\section{Behavioral measures}

For behavioral analysis at the 6 week time point, rats were tested on object location, elevated plus maze, and social recognition/preference. These tests were used because they are known to involve the hippocampus and/or appear to be affected by changes in adult neurogenesis (McHugh et al., 2004; Mak and Weiss, 2010; Morris et al., 2013). Rats were tested on these three measures over $2 \mathrm{~d}$, with the order of testing counterbalanced. Rats were perfused the day after the last test. On each testing day, rats were habituated to the testing room for at least $30 \mathrm{~min}$ before the first test of the day.

Object location. To assess recognition of a novel location for a previously encountered object, rats were placed in an open field with opaque walls $(17.5 \times 17.5 \times 17.5$ inches) with two identical objects (plastic, each $\sim 36$ cubic inches) for 3 min (Barker and Warburton, 2011). Rats were 
removed for $5 \mathrm{~min}$ while one of the objects was moved to the opposite side of the chamber. The left/right position of the moved object was counterbalanced between each rat. Rats were then returned to the chamber for $3 \mathrm{~min}$. A discrimination ratio was calculated for time spent investigating the moved object versus the object that was not moved. Investigating the moved object more than the nonmoved object is considered to be evidence for object location memory.

Anxiety testing. To assess anxiety-like behavior, the elevated plus maze was used (Pellow and File, 1986; Lister, 1987; Walf and Frye, 2007; Staples and Cornish, 2014). Rats were placed on an elevated plus-shaped track ( $44 \times 44 \times 20$ inches). Two of the arms had high walls (13 inches), whereas the other two arms and central intersection were open. All arms were 20 inches in length, dimly lit by reflected light. Exploratory behavior was measured for $5 \mathrm{~min}$ and analyzed. Number of entries into the open and closed arms and time spent in the open arms were measured for each rat. Because the open arms are more exposed to the light and open air, more time spent in the open arms is considered a measure of reduced anxiety (Sun et al., 2013). Total entries into both closed and open arms are considered a measure of locomotion (File and Aranko, 1988).

Social recognition and novelty preference testing. Social recognition and novelty preference were tested using an apparatus based on previous social behavior studies done in mice, with dimensions scaled up to accommodate rats (Engelmann et al., 1995; Moy et al., 2004; Crawley, 2007; Eagle et al., 2013). This apparatus was made of Plexiglas and was $40 \times$ $10 \times 12$ inches. Removable Plexiglas dividers perforated with $1-\mathrm{cm}$ diameter holes were placed on each side of the apparatus to create two side chambers that were each $10 \times 10 \times 10$ inches. These walls allowed the test rat to see, smell, and hear stimulus rats while preventing the possibility of physical interaction. Before testing, test rats were placed in a standard cage with a novel rat for $5 \mathrm{~min}$, because this time is sufficient to produce social recognition 30 min later (Thor and Holloway, 1982; Popik et al., 1992). Twenty-five minutes after the end of the 5 min exposure, test rats were placed in the social recognition apparatus for a 5 min habituation; during this period, the side chambers were empty. After this habituation, the familiar rat was placed in one chamber and a novel rat was placed in the other chamber. The side of the chamber with the familiar rat was counterbalanced for each rat. Behavior of the test rat was recorded and analyzed for grooming, rearing, investigation, and resting on each half of the apparatus. Investigation was defined as active sniffing of each Plexiglas wall and was analyzed to assess recognition of the familiar rat (van der Kooij and Sandi, 2012). After a 10 min testing phase, all rats were returned to home cages. The discrimination ratio of time spent investigating each rat over the total time investigating both rats was calculated. The discrimination ratio was also calculated for total time spent resting near each rat, excluding investigation time, to assess rats' resting social novelty preference behavior. To assess social novelty preference behavior in additional detail, resting behavior after investigation (crossing to the other side of the chamber vs staying on the same side) was measured for each rat. In addition, we assessed incomplete and reversed crossings from one side of the testing apparatus to the other as a potential measure of vicarious trial and error (VTE; Redish 2016).

Ultrasonic vocalizations (USVs) were measured for the duration of the social preference study using the UltraSoundGate $116 \mathrm{Hb}$ recorder $(116 \mathrm{Hb} /$ 41; Avisoft Bioacoustics) and analyzed using Avisoft-RECORDER and SASLab Lite software. Recordings were analyzed for 22 and $50 \mathrm{kHz}$ vocalizations, typically associated with threatening and rewarding stimuli, respectively (Brudzynski, 2013).

\section{Histology}

At 2 or 6 weeks, rats were anesthetized with Euthasol and perfused with $4.0 \%$ paraformaldehyde in $0.1 \mathrm{~m}$ phosphate buffer. At $48 \mathrm{~h}$ after fixation, coronal sections $(40 \mu \mathrm{m})$ were cut throughout the entire rostrocaudal extent of the dentate gyrus (DG) on a vibratome into a bath of $0.1 \mathrm{M}$ PBS, $\mathrm{pH}$ 7.5. Brains were analyzed for the following: (1) IdU, to assess the survival of new neurons generated before social disruption; (2) CldU, to assess the proliferation and survival of new neurons generated after social disruption; (3) BrdU, to assess the number of new neurons generated in GFAP-TK rats fed GCV or vehicle; (4) doublecortin (DCX), to label immature neurons; (5) GFAP, to determine changes in glial cells; (6)
Sox2, to determine changes in pluripotent progenitors; and (7) Sox2/ GFAP colabeling to assess changes in radial glia-like precursors. Because receptors for oxytocin and vasopressin are expressed in the hippocampus (both neuropeptides are involved in social behavior, stress responses, and neurogenesis; Albeck et al., 1997; Alonso et al., 2004; Leuner et al., 2012) and oxytocin receptor (OTR) binding has been shown to increase in the ventral hippocampus with stress (Liberzon and Young, 1997), we examined OTRs and vasopressin la receptors (V1aRs), the main vasopressin receptor type expressed in the hippocampus. We also analyzed $\mathrm{OTR} / \mathrm{Ki} 67^{+}$and $\mathrm{V} 1 \mathrm{aR} / \mathrm{Ki} 67^{+}$colabeling to assess the expression patterns of OTRs and V1aRs on proliferating neuronal precursors. All immunolabeling was performed on sections from groups to be compared simultaneously to minimize variability. We also examined the immunolabeling pattern for OTR and V1aR in the hypothalamus to verify that both antibodies produce staining results that are consistent with binding data (Tribollet et al., 1988; Kremarik et al., 1995). Dorsal and ventral distinctions were made within hippocampal hemisections according to published guidelines (Banasr et al., 2006).

For IdU/CldU/BrdU peroxidase staining, a 1:12 series of sections was mounted onto glass slides and stained according to established protocols (Leuner et al., 2009). For microscopic data analysis, the slides were coded, and IdU/CldU/BrdU-labeled cells in the granule cell layer (GCL), subgranular zone (SGZ), and the hilus were counted on every 12th halfsection through the DG with $100 \times$ oil objective on an Olympus BX-60 microscope. The numbers were tallied for the DG and GCL-SGZ and multiplied by 24 to obtain a stereological estimate for the brain region.

Double labeling with immunofluorescence for IdU/CldU and the immature neuronal marker DCX or BrdU and the neuronal marker neuronal nuclei (NeuN) was performed on free-floating sections to determine whether the newly labeled cells were immature neurons according to established protocols (Kempermann et al., 2003). For double labeling, the percentage of IdU/CldU-labeled GCL cells expressing DCX was determined by analyzing 25 IdU/CldU-labeled cells per brain using a Zeiss Axiovert confocal laser scanning microscope (510 LSM; argon 458/488 $\mathrm{nm}$ and helium-neon $543 \mathrm{~nm}$ ). For examining endogenous markers of immature neurons and progenitor cells, the tissue was incubated in primary antibodies against DCX, Sox2, Ki67, and GFAP according to previously published protocols (Suh et al., 2007; Lugert et al., 2010).

For labeling OTRs and V1aRs, free-floating tissue was incubated with rabbit anti-OTR (1:150; Alpha Diagnostics) and rabbit anti-V1aR (1:150; Alpha Diagnostics). For cell density measurements, tissue was counterstained using Hoechst 33342 (1:1000; Invitrogen), and volume measurements of the DG were taken using StereoInvestigator software (MBF Bioscience). Total $\mathrm{DCX}^{+}$, Sox $2^{+}$, and $\mathrm{GFAP}^{+}$(radial and horizontal morphologies) were counted on every 12th half-section through the DG with $100 \times$ oil objective on an Olympus BX-60 microscope. The raw counts for each section were divided by the volume of the DG to obtain a density measurement. Fifty Sox ${ }^{+}$cells in the DG ( 25 dorsal, 25 ventral) per brain were scanned and analyzed for $\mathrm{GFAP}^{+}$colabeling using a Zeiss Axiovert confocal laser scanning microscope (510 LSM; argon 458/488 $\mathrm{nm}$ and helium-neon $543 \mathrm{~nm}$ ). A distinction was made between GFAP cells with radial and horizontal morphology because previous studies have shown that $\mathrm{GFAP}^{+} / \mathrm{Sox}^{+}{ }^{+}$cells with radial morphology represent radial glia-like precursor cells with stem cell-like properties, whereas $\mathrm{GFAP}^{+} / \mathrm{Sox}^{+}{ }^{+}$cells with horizontal morphology represent type $2 \mathrm{a}$ intermediate/transit amplifying progenitor cells that are not yet neuronally committed (Lugert et al., 2010).

OTR and V1aR expression was measured for mean optical intensity using $1-\mu \mathrm{m}$-thick optical sections of the DG. For these analyses, the DG within a single hemisection was imaged in its entirety, with 10 images obtained for each brain. Five representative $1 \mu \mathrm{m}$ optical slices from the dorsal and ventral DG were scanned and measured for optical intensity from each brain using a Zeiss Axiovert confocal laser scanning microscope ( $510 \mathrm{LSM}$; argon 458/488 nm and helium-neon $543 \mathrm{~nm}$ ). Intensity was calculated using LSM 510 software. Regions of interest (ROIs) were manually defined to include the dorsal GCL and ventral GCL. The fornix was used for a measure of background staining because this region had no OTR or VlaR staining in any of the brains analyzed. Raw ROI intensity values were divided by fornix intensity within the same pixel-size 
ROI on the same scan of each slice to control for variability in staining intensity between sections. Normalized brightness per ROI was determined for each pixel of a given ROI as the fractional increase in brightness at that pixel over the mean brightness of the fornix, according to the following formula: (mean intensity of the region - mean intensity background)/mean intensity background. To analyze OTR and V1aR staining on individual $\mathrm{Ki}^{+} 7^{+}$proliferating cells, $50 \mathrm{Ki}^{+}{ }^{+}$cells were scanned from the DG within a hemisection (25 dorsal, 25 ventral). Using LSM 510 software, each $\mathrm{Ki}_{67}{ }^{+}$cell body was traced, and the brightness of OTR or $\mathrm{V} 1 \mathrm{aR}$ pixels was determined within the tracing. This was assessed with respect to the background brightness within an area of the same size of the tracing adjacent to each labeled cell (Siegel et al., 1993; Schoenfeld et al., 2014).

\section{Statistical analysis}

Depending on the number of groups in an experiment, unpaired Student's $t$ tests or one or two-way ANOVA, followed by Bonferroni's post hoc comparisons were used.

\section{Results}

\section{Social disruption results in increased aggression and dominance hierarchy destabilization}

Throughout the $6 \mathrm{~d}$ period of living in the VBS, the overall level of aggression changed significantly $\left(F_{(2,14)}=12.97, p=0.001\right.$; Fig. $1 C)$. Between days 1 and 3, the level of aggression decreased for both groups (stable and disrupted; $p=0.005)$. In stable cohorts, aggression did not change from day 3 to $6(3.87 \pm 0.56$ vs $4.09 \pm$ 0.60 acts/rat, $\left.t_{(8)}=-0.27, p=0.821\right)$, but in disrupted cohorts, after the dominant rats were switched between two hierarchies, the level of aggression increased significantly from day 3 to 6 ( $p=$ 0.001; Fig. 1C).

Postdisruption aggression levels were also significantly higher than day 1 aggression levels ( $p=0.0001$; Fig. $1 C$ ). Switched dominants showed a significant decrease in dominance score (aggressive acts - defensive acts) from $5.7 \pm 1.6$ to $0.2 \pm 1.5$ [two-way repeated-measures ANOVA, interaction of phase (before switch vs after switch), and dominance score, $F_{(1,38)}=10.294, p=$ 0.003 ]. In every instance, switching dominants led to a loss of dominant status for these animals. In other words, hierarchy disruption led to an increase in aggression that exceeded that of naive rats placed in the VBS for the first time, as well as to a reorganization of the social hierarchy with no evidence of a clear dominant, and loss of position by previously dominant rats.

\section{Social disruption suppresses adult neurogenesis in the hippocampus}

Consistent with previous results (Kozorovitskiy and Gould, 2004), we found that dominants in a stable hierarchy had more new neurons in the ventral DG than subordinates (IdU, $6552 \pm$ 840 in dominants vs $4448 \pm 480$ in subordinates, $t_{(13)}=2.41 ; p=$ $0.032)$. However, social disruption eliminated the advantage of being dominant in dominants (IdU, $3300 \pm 607$ in dominants vs $2762 \pm 218$ in subordinates, $\left.t_{(13)}=-1.07, p=0.3\right)$. Because the dominant - subordinate difference in new cell number in stable groups was no longer present in socially disrupted groups and was irrelevant for control groups, data were collapsed across dominance status for subsequent analyses, and experiments focused on control compared with disrupted hierarchy groups. No differences were observed between rats that were pair-housed in standard cages and those that were switched between cages, suggesting that switching location or being housed with a new conspecific did not alter baseline levels of neurogenesis (e.g., for ventral DG IdU, $4824 \pm 363$ in switched vs $5580 \pm 1222$ in nonswitched; $\left.t_{(6)}=0.59 ; p=0.57\right)$. Furthermore, no differences were observed between control and stable VBS cohorts (exclud- ing dominant rats) on any measure of cell proliferation or adult neurogenesis ( $p>0.05$ for all comparisons), suggesting that living in a VBS, even under stable conditions, did not produce any measurable change in neurogenesis. As shown previously (Kozorovitskiy and Gould, 2004), cage controls and subordinates in a stable hierarchy did not differ on measures of adult neurogenesis. Thus, subsequent comparisons were made between nonswitched control and disrupted groups.

Social disruption produced a decrease in the numbers of neuronal precursor cells and immature neurons compared with control groups at the 2 week time point. The number of Sox $2^{+}$cells $\left(t_{(6)}=-2.68, p=0.037\right)$ and $\mathrm{GFAP}^{+}$cells with radial morphology $\left(t_{(6)}=-3.73, p=0.01\right)$ were decreased in the ventral DG after social disruption compared with control (Fig. $1 E, F)$. No changes were observed in horizontal GFAP ${ }^{+}$cells $(p=0.53)$, the proportion of radial to horizontal cells $(p=0.23)$, or the degree of colabeling of Sox 2 and GFAP $(p=0.26)$ with social disruption, indicating that the observed decreases were in Sox $2^{+} / \mathrm{GFAP}^{+}$ radial glia-like precursor cells. In addition, no changes were observed on any of these measures in the dorsal DG $(p>0.05$ for all such comparisons). Social disruption also produced a decrease in the number of immature neurons (labeled with DCX) in the ventral DG compared with controls at the 2 week time point $\left(t_{(6)}=3.07, p=0.022\right.$; Fig. $\left.1 E, F\right)$. Similar to what was observed for neuronal precursors, the suppressive effects of social disruption on $\mathrm{DCX}^{+}$cells were not seen in the dorsal DG $(p=0.21)$. Social disruption also decreased the number of new cells in the ventral DG labeled before the disruption (IdU, $t_{(21)}=4.31, p=$ $0.002)$, as well as the number of new cells in the ventral DG labeled after the disruption (CldU, $\left.t_{(22)}=4.32, p=0.001\right)$ compared with controls at the 2 week time point (Fig. $1 D, F$ ). No differences were observed in the numbers of $\mathrm{IdU}^{+}$or CldU ${ }^{+}$cells in the SVZ, suggesting that these effects may have been specific to the hippocampus ( $p>0.05$ for all comparisons).

More than $80 \%$ of $\mathrm{IdU}^{+}$and $\mathrm{CldU}^{+}$cells colabeled with the immature neuronal marker DCX. There were no differences in the percentage of IdU- or CldU-labeled cells that expressed DCX among any of the groups examined $(p>0.05)$, suggesting that the changes in IdU- or CldU-labeled cell number associated with disruption represent suppressed adult neurogenesis.

At the 6 week time point, the difference between control and disrupted groups in the ventral DG no longer existed for cells generated before the disruption (IdU, $3141 \pm 295$ in control vs $2621 \pm 323$ in disrupted, $p>0.05)$, but a persistent decrease in the number of cells generated after the disruption (CldU, $3174 \pm$ 416 in control vs $1854 \pm 169$ in disrupted; $t_{(6)}=-2.94, p=0.026$ ) remained in this region. At the 6 week time point as well, there were no persistent differences in the number of $\mathrm{DCX}^{+}$cells in the ventral DG $(4293 \pm 374$ in control vs $5327 \pm 1129$ in disrupted; $\left.t_{(9)}=-0.94, p=0.372\right)$, suggesting that the rate of immature neuron production had returned to baseline. The lower numbers of DCX cells in this experiment may be attributable to the switch in housing from group living to individual living. At the 6 week time point, there were no significant differences between control and disrupted groups in the dorsal DG for any measure $(p>0.05)$.

\section{Social disruption did not alter $\mathrm{OTR}^{+}$or $\mathrm{V} \mathrm{aR}^{+}$labeling in proliferating cells in the DG}

The staining pattern of both OTR and V1aR in the hypothalamus (Fig. $1 F$ ) was similar to what has been reported in binding studies (Tribollet et al., 1988; Kremarik et al., 1995), including high OTR labeling in the ventromedial hypothalamus compared with the 
lateral hypothalamus, as well as high V1aR in the suprachiasmatic nucleus compared with the surrounding regions, including the medial preoptic area, suggesting that this labeling reflects receptors for oxytocin and vasopressin. Also consistent with previous reports showing that OTR binding was increased in the ventral hippocampus of stressed rats (Liberzon and Young, 1997), we observed increased optical intensity for OTR in disrupted hierarchy rats compared with controls in the ventral DG $\left(t_{(10)}=2.72\right.$, $p=0.022)$ but not dorsal DG $(p>0.05$; Fig. $1 G)$. There were no differences in V1aR expression in dorsal or ventral DG between disrupted and control groups ( $p>0.05$ for both comparisons). OTR and V1aR expression was observed on $\mathrm{Ki}^{+} 7^{+}$proliferating cells in the DG, but the proportion of $\mathrm{Ki}^{+}{ }^{+}$cells that expressed either of these receptors did not differ between groups in dorsal or ventral DG ( $p>0.05$ for all comparisons; Fig. $1 G)$.

\section{Social disruption results in lower baseline levels of CORT}

Plasma CORT levels differed among rats living in different social settings on day 6 but not in a predicted manner. Although we anticipated that social disruption would result in elevated CORT levels, we found that it did not, at least persistently. Instead, social disruption resulted in decreased baseline CORT levels $(102 \pm 36.1 \mathrm{ng} / \mathrm{ml}$ in control, $31.96 \pm 22.5 \mathrm{ng} / \mathrm{ml}$ in disrupted; $\left.t_{(12)}=1.96, p=0.036\right)$. Plasma testosterone levels did not differ significantly between groups $(106.1 \pm 27$ $\mathrm{ng} / \mathrm{ml}$ in control, $243.4 \pm 88.8 \mathrm{ng} / \mathrm{ml}$ in disrupted; $p>0.05)$.

\section{Social disruption produced lasting changes in social behavior without impairing performance on some hippocampus-dependent tasks}

Performance on the object location task did not differ between rats from disrupted hierarchies and rats from standard group housing (discrimination ratio, $t_{(12)}=0.21, p>0.05$; Fig. $1 H$ ). Preference for resting near objects located in novel versus familiar locations was not detected in either group. On the elevated plus maze, rats from disrupted hierarchies entered the open arms more than controls and spent more time in the open arms than controls (proportional entries into open arms, $t_{(29)}=3.04, p=$ 0.004 ; time in open arms, $t_{(20)}=-2.26, p=0.03$; Fig. $1 I$ ).

Social recognition did not differ between the control and disrupted groups, with both groups showing more time spent investigating a novel conspecific compared with a familiar conspecific (two-way ANOVA of condition vs novelty, main effect of novelty, $\left.F_{(1,55)}=9.29, p=0.004\right)$, and total number of investigations of novel or familiar rats did not differ between groups. However, substantial differences were noted among the groups when social resting preference was analyzed. Whereas control rats tended to rest in the proximity of the novel rat, rats from a disrupted hierarchy preferred to rest in the proximity of a familiar rat (control preference compared with disrupted preference, $t_{(14)}=2.83, p=$ 0.013 ; Fig. $2 B$ ). That is, disrupted rats had a greater propensity to cross the chamber to rest near a familiar rat after investigation of the novel rat (Fig. 2C). In contrast, control rats preferred to rest near the novel rat after investigation of the novel rat (proportional crosses to familiar after investigating novel, $t_{(9)}=4.24, p=$ 0.002; Fig. 2C). We further analyzed the behavior of rats after investigation of the novel rat and found that control rats often initiated a movement path toward the opposite side of the social chamber, in the direction of the familiar rat, but hesitated and turned back to rest by the novel rat, suggesting a behavior similar to what has been described as reflecting VTE in maze studies (Redish, 2016). In contrast, disrupted rats displayed significantly less VTE-like behavior and most often turned from the novel rat after investigation and took a direct path to the familiar rat to rest. In controls, VTE-like behavior occurred to a much lesser extent after investigation of the familiar rat compared with the novel rat, and this was unchanged in disrupted rats (see Fig. 5). Thus, compared with controls, disrupted rats exhibited fewer instances of VTE-like behavior after investigating the novel stimulus rat but not the familiar stimulus rat (see Fig. 5; social disruption group $\times$ stimulus rat interaction, $\left.F_{(1,16)}=8.67, p=0.001\right)$. These results appear independent of general anxiety measures within the social preference apparatus, because we did not observe differences in behavior during habituation to the social chamber (in the absence of conspecifics), including center crossing and active time (Fig. 2D). After addition of conspecifics to the chamber, rearing and grooming behavior, sometimes used as measures of anxiety (Daniels et al., 2008), did not vary between control and disrupted groups in either duration of these behaviors or side preference (Fig. 2E, F; $p>0.05$ for all comparisons). Furthermore, in the presence of conspecifics, no test rats from either control or disrupted groups emitted USVs in the $22 \mathrm{kHz}$ range, which are typically associated with threatening stimuli (Fig. 2G, $H$ ). Instead, rats in both groups emitted $50 \mathrm{kHz}$ vocalizations, which are typically associated with neutral or rewarding stimuli (Brudzynski, 2013). Together, these findings suggest that social disruption alters social resting preference without adversely affecting social recognition, object location memory, or social anxiety levels.

\section{Oxytocin restored adult neurogenesis and social preference in socially disrupted rats}

As expected from previous findings (Leuner et al., 2012), daily oxytocin treatment for 1 week after social disruption increased $\mathrm{DCX}^{+}$cells in the ventral DG $\left(t_{(16)}=2.37, p=0.031\right)$ but not the dorsal DG $\left(t_{(18)}=0.56, p=0.58\right.$; Fig. $\left.3 B, C\right)$. Four weeks after the end of oxytocin treatment, oxytocin-treated rats did not show any difference in anxiety-like behavior in the elevated plus maze compared with vehicle-treated rats (proportional time in open arms, $0.21 \pm 0.06$ in disrupted + vehicle vs $0.17 \pm 0.06$ in disrupted + oxytocin; $t_{(14)}=0.44, p=0.66$ ). Likewise, rats preferred to investigate a novel rat over a familiar rat, regardless of whether they had been treated with oxytocin (two-way ANOVA of condition vs novelty; main effect of novelty, $F_{(1,13)}=6.59, p=0.028$ ). As previously observed for socially disrupted rats (Fig. $2 B$ ), rats from a disrupted hierarchy that received vehicle injections displayed a preference for resting near a familiar, as opposed to novel, rat (Fig. 3C). This preference was reversed in socially disrupted rats with oxytocin treatment (Fig. 3C). Rats that received oxytocin lost their preference for familiarity, changing strategy to rest near the novel, as opposed to the familiar, rat $\left(t_{(30)}=3.13\right.$, $p=0.003)$, similar to what was observed in naive rats without social disruption (compare with Fig. $2 B$ ). These differences were driven by both increased propensity to cross to the familiar side to rest after novel investigation and remaining on the familiar side to rest after investigating the familiar rat (Fig. 3D). In addition, rats that had restored neurogenesis after oxytocin treatment showed an increase in VTE-like behavior after investigating the novel stimulus rat that was comparable with controls (see Fig. 5), whereas no change was observed in VTE-like behavior after investigating the familiar stimulus rat (see Fig. 5; oxytocin treatment $\times$ stimulus rat interaction, $\left.F_{(1,12)}=18.62, p=0.001\right)$. These findings suggest that oxytocin treatment after social disruption restores levels of adult neurogenesis, and, 1 month after oxytocin treatment, social resting preference behavior is restored to control values without changing social recognition or general anxiety-like behavior. 
A
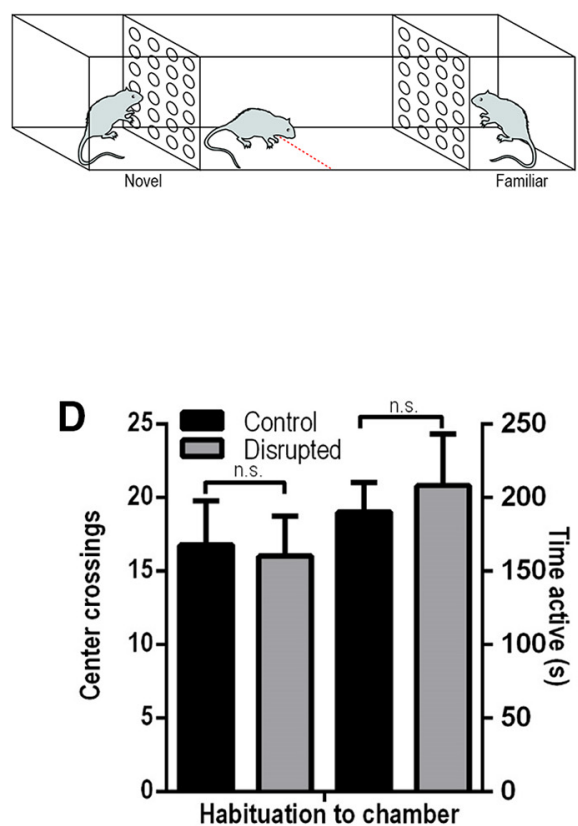

G

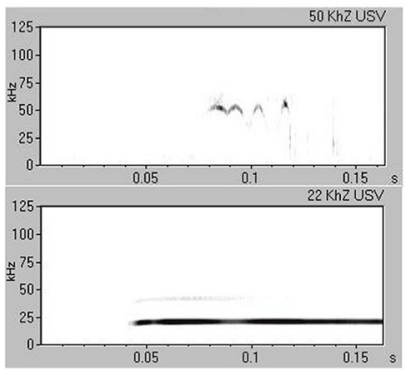

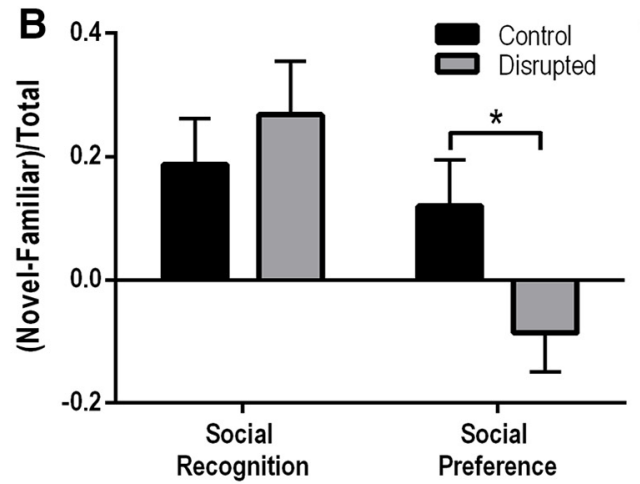

E

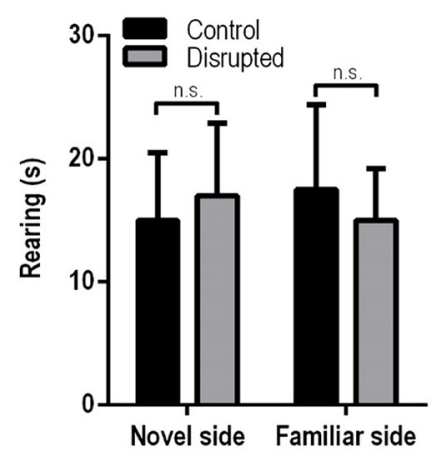

H

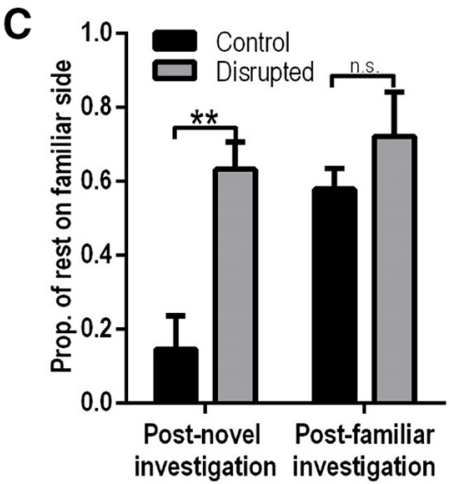

$\mathbf{F}$

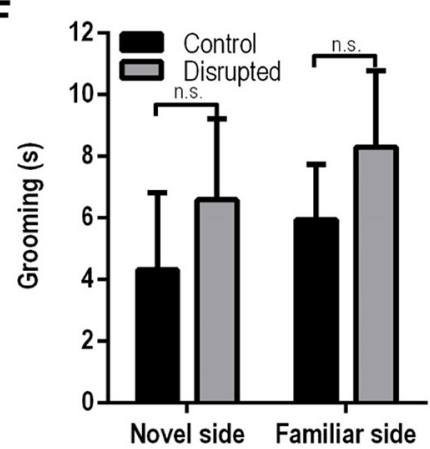

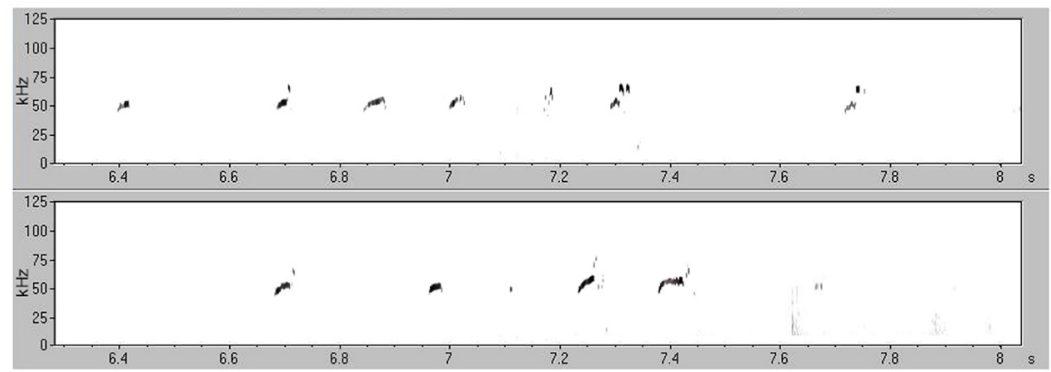

Figure 2. Social disruption has a lasting effect on social behavior. $A$, Schematic of social testing apparatus. $B$, Social disruption produces no deficits in the ability to recognize a familiar conspecific, because both control and disrupted groups investigate a novel rat more than a familiar rat. Whereas rats from standard group housing showed a preference for resting near a novel rat, rats from a disrupted hierarchy prefer to rest near a familiar rat. Values $>0$ indicate a preference for the novel rat; values $<0$ indicate a preference for the familiar rat. $C$, Differences in social preference are driven by behaviors after investigation of the novel rat: rats from a disrupted hierarchy prefer to cross the chamber to rest near the familiar rat, whereas both groups show similar resting behaviors after investigation of the familiar rat. $\boldsymbol{D}$, Before the addition of stimulus rats, groups exhibited the same amount of activity, in terms of both center crossings and time spent mobile in the chamber. $\boldsymbol{E}$, There were no group differences in side localization or duration of rearing behavior. $\boldsymbol{F}$, There were no group differences in side localization or duration of grooming behavior. $\boldsymbol{G}$, Examples of the two USV types that rats emit; $50 \mathrm{kHz}$ USVs are primarily associated with neutral or positive valence, whereas $22 \mathrm{kHz}$ USVs are associated with danger or negative valence. $\boldsymbol{H}$, Sample USVs emitted by rats from the control group (top) and the disrupted group (bottom) after introduction of the stimulus animals. No rats emitted $22 \mathrm{kHz}$ USVs during the social test. Bars indicate mean $+\mathrm{SEM}$. ${ }^{*} p<0.05,{ }^{* *} p<$ 0.01. n.s., No significant difference.

Suppressed adult neurogenesis in socially naive GFAP-TK rats reversed social preference

GCV treatment was effective in reducing adult neurogenesis in GFAP-TK rats, because BrdU ${ }^{+}$cells were lower in both the dorsal and ventral DG compared with in GFAP-TK rats treated with vehicle $\left(t_{(15)}=2.56, p=0.022\right.$ for dorsal DG; $t_{(15)}=3.18, p=$ 0.006 for ventral DG; Fig. $4 B$ ). There was no effect of GCV treatment on the proportion of $\mathrm{BrdU}^{+}$cells colabeled with NeuN in the DG $(0.91 \pm 0.04$ for $\mathrm{TK}+$ vehicle vs $0.88 \pm 0.01$ for $\mathrm{TK}+$ $\left.\mathrm{GCV} ; t_{(8)}=-0.77, p=0.46\right)$, indicating that the number of new neurons was decreased. Importantly, the decrease in new neurons was not complete with this treatment of GCV and instead quantitatively resembled the decrease we observed after social disruption in wild types (compare Figs. 4B, 1D). GCV treatment also decreased the number of BrdU-labeled cells in the SVZ from $3704 \pm 240$ to $2436 \pm 180\left(t_{(6)}=-4.28, p=0.008\right)$. When tested behaviorally 6 weeks after the last GCV treatment, no significant differences were observed between GCV- and vehicle-treated TK rats on object location $(0.22 \pm 0.19$ for TK + vehicle vs $0.36 \pm$ 0.31 for $\left.\mathrm{TK}+\mathrm{GCV} ; t_{(17)}=1.21, p=0.2\right)$. There were also no effects on the proportion of time spent in the open arms of the elevated plus maze, indicating no difference in anxiety-like behavior $(0.43 \pm 0.03$ for $\mathrm{TK}+$ vehicle vs $0.49 \pm 0.01$ for $\mathrm{TK}+$ $\left.\mathrm{GCV} ; t_{(20)}=1.46, p=0.15\right)$. In addition, social recognition did not differ between vehicle- and GCV-treated rats (two-way ANOVA of condition vs novelty; main effect of novelty, $F_{(1,15)}=$ $6.51, p=0.03$ ). Like socially disrupted wild-type rats, socially naive GFAP-TK rats treated with GCV showed a preference for resting near a familiar rat, whereas socially naive GFAP-TK rats treated with vehicle showed a preference for resting near a novel rat $t_{(18)}=2.6$, $p=0.02$; Fig. $4 C$ ). These differences were driven by both increased propensity of GCV-treated rats to cross to the familiar side to rest 
A

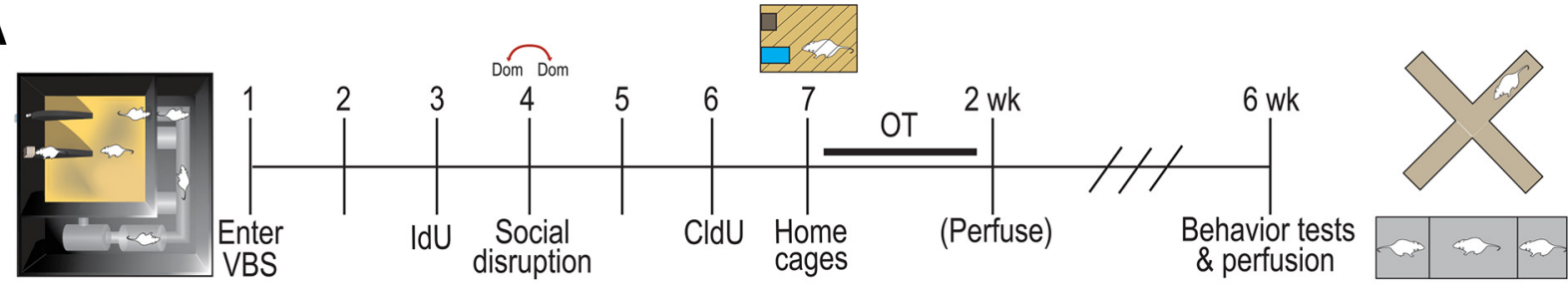

B

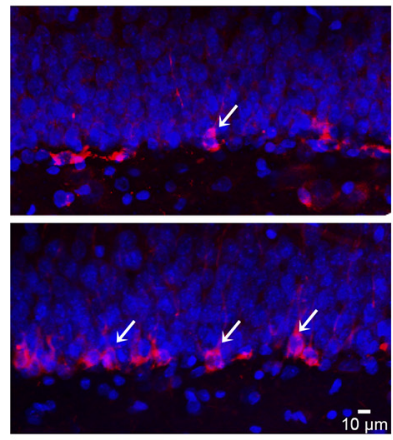

C

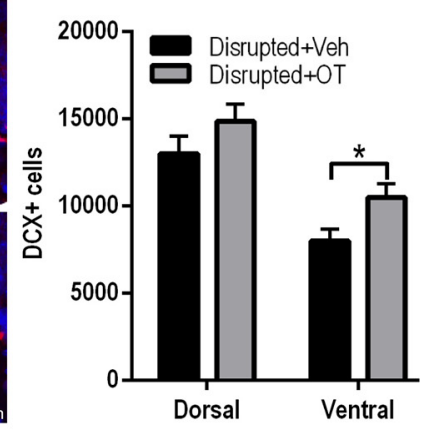

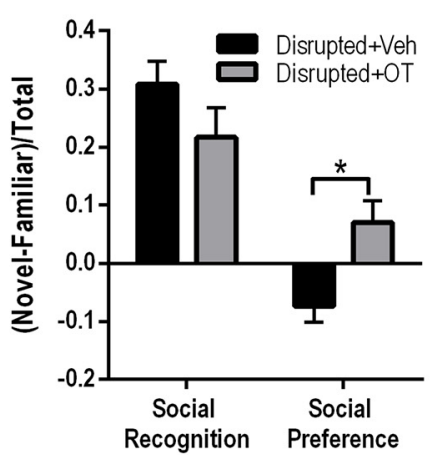

D

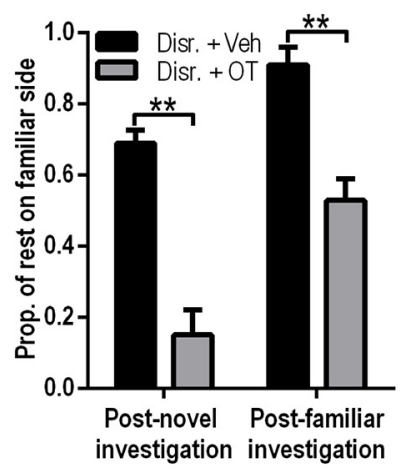

Figure 3. Oxytocin treatment after social disruption increases the number of immature neurons in the ventral $D G$ and restores a resting preference for novelty. $A$, Timeline for hierarchy, neuronal birthdating, oxytocin (OT) treatment, and behavioral testing. $\boldsymbol{B}$, Left, Representative image of ventral DG in a rat from a disrupted hierarchy treated with vehicle (Veh; top) or $1 \mathrm{mg} / \mathrm{kg} 0 \mathrm{OT}$ (bottom) daily for 1 week after leaving the VBS, with DCX ${ }^{+}$immature neurons indicated with arrows. Red, DCX; blue, Hoechst 33342. Right, Rats treated with 0T after social disruption showed an increase in immature neurons in the ventral DG. C, Social recognition is not affected by $0 \mathrm{~T}$ administration after social disruption, whereas rats treated with $0 \mathrm{~T}$ prefer to rest near the novel rat. Values $>0$ indicate a preference for the novel rat; values $<0$ indicate a preference for the familiar rat. $D, 0$ T-treated rats are more likely to rest near the novel rat after investigation of either side. Bars indicate mean + SEM. ${ }^{*} p<0.05,{ }^{* *} p<0.01$.

after novel investigation and to remain on the familiar side to rest after investigating the familiar rat (Fig. 4D). In addition, GFAP-TK rats with lowered neurogenesis (after GCV treatment) showed fewer incidents of VTE-like behavior after they investigated the novel stimulus rat compared with rats with control values of neurogenesis (after no GCV treatment) and no such change in VTE-like behavior after they investigated the familiar stimulus rat (Fig. 5; GCV group $\times$ stimulus rat interaction, $\left.F_{(1,16)}=13.79, p=0.002\right)$. No significant differences in baseline CORT levels were observed between GFAP-TK rats treated with GCV and wild-type controls (158.8 \pm $39.8 \mathrm{ng} / \mathrm{ml}$ in WT, $206.0 \pm 34.1 \mathrm{ng} / \mathrm{ml}$ in GFAP-TK; $t_{(9)}=0.87$, $p=0.41)$.

\section{Discussion}

Our results show that disrupting an established dominance hierarchy changes the rate of adult neurogenesis in the hippocampus and that these changes may be related to lasting adaptations in social behavior. Social disruption suppressed the numbers of progenitor cells and new neurons for all members of a dominance group. At a later time when new neurons generated during social disruption had time to integrate into the circuitry, rats from a disrupted hierarchy exhibited a preference for resting near a familiar, rather than novel, rat, without notable impairments in social recognition, cognition, or anxiety regulation. Increasing adult neurogenesis with oxytocin administration after social disruption restored control-typical social preference behavior, and suppressing adult neurogenesis with transgenic manipulation produced a familiar preference in socially naive rats. These data suggest that social disruption may fine tune subsequent social behavior, at least in part, by reducing the number of new neurons in the DG.

The reduction in the number of new neurons with social disruption was observed regardless of dominance position and may have occurred as a result of the stressful effects of persistent aggression (Czéh et al., 2002). However, somewhat paradoxically, rats from a disrupted VBS exhibit lower levels of plasma CORT than rats from stable hierarchies and control conditions. This may reflect hypocortisolism, a phenomenon wherein chronic stress downregulates the hypothalamic-pituitary-adrenal axis response (Yehuda et al., 1990; Rohleder et al., 2004). Although this can lead to psychopathology, hypocortisolism may also reflect an adaptive response to chronic stress (McEwen, 1998; Fries et al., 2005). The hippocampus is dense with OTRs, which may play a role in lowering CORT levels after stress (Gimpl and Fahrenholz, 2001). The increase in hippocampal OTR immunolabeling we observed with social disruption may be linked to lower CORT levels. Along these lines, proactive stress-coping styles can suppress basal CORT levels (Korte et al., 1996; Koolhaas et al., 2010); increased aggression after social disruption and suppressed anxiety-like behavior also suggest that our disrupted rats have developed a proactive phenotype (Veenema and Neumann, 2007). Our observations are consistent with data showing proactive coping (Garrett et al., 2015) and suppressed anxiety (Tsai et al., 2015) in adult mice with conditional suppression of immature neurons (but see Snyder et al., 2011; Deng and Gage, 2015).

We used oxytocin administration to stimulate neurogenesis after social disruption and found a reversal of the social behavior change. Together with our findings that reduced adult neurogenesis in transgenic socially naive rats mimics the social behavior change we observed with social disruption, these findings suggest that a similar adult neurogenesis mechanism influences social behavior in each case. However, we cannot rule out the possibility that similar changes in social behavior are occurring through different mechanisms in these conditions. Although oxytocin manipulation ended 4 weeks before behavioral testing, postdis- 
A
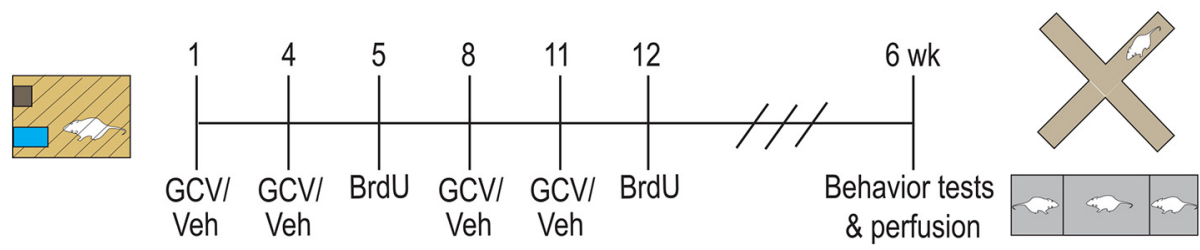

B
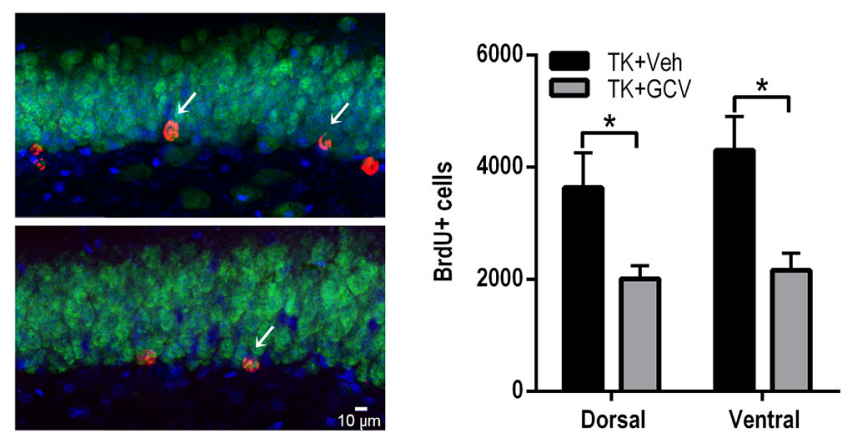

C
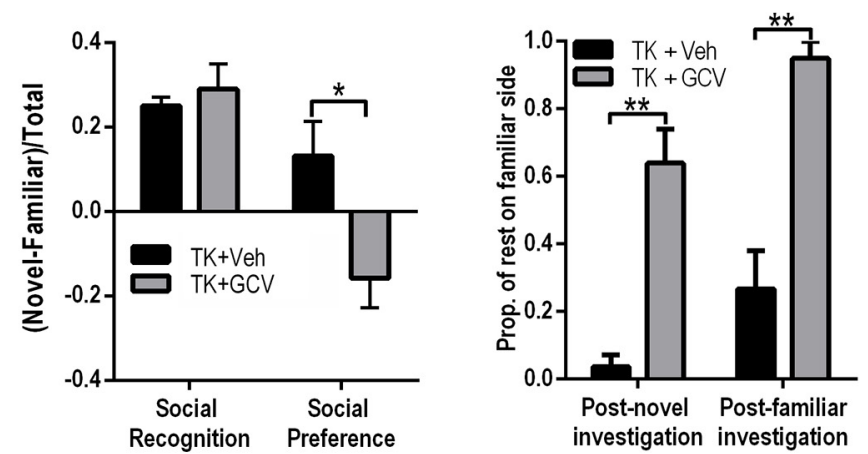

Figure 4. GFAP-TK rats treated with GCV show a suppression in adult neurogenesis in the DG and exhibit a resting preference for a familiar rat. $A$, Timeline for neuronal birthdating, drug treatment, and behavioral testing for GFAP-TK rats. B, Left, Representative image of ventral DG of GFAP-TK rat treated with vehicle (Veh; top) or GCV (bottom) for a 2 week period. Red, BrdU; green, NeuN; blue, Hoechst 33342. Right, GFAP-TK rats treated with GCV showed a suppression in BrdU ${ }^{+}$neurons in the DG. C, GFAP-TK rats with a suppressed pool of 6-week-old neurons show no impairments to recognizing a novel rat but exhibit a resting preference for a familiar rat. Values $>0$ indicate a preference for the novel rat; values $<0$ indicate a preference for the familiar rat. $D$, GFAP-TK rats with a suppressed pool of 6-week-old neurons prefer to rest near the familiar rat after investigation of either side. Bars indicate mean + SEM. ${ }^{*} p<0.05,{ }^{* *} p<0.01$.

A
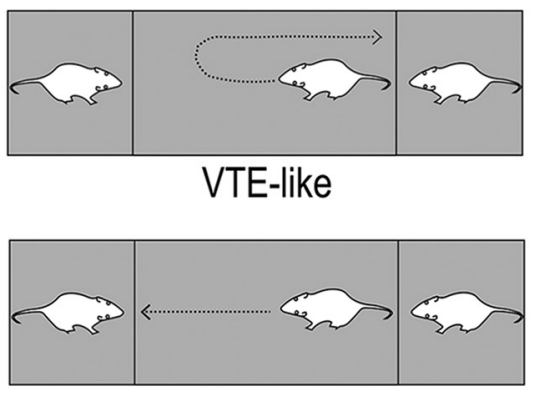

Non VTE-like
B

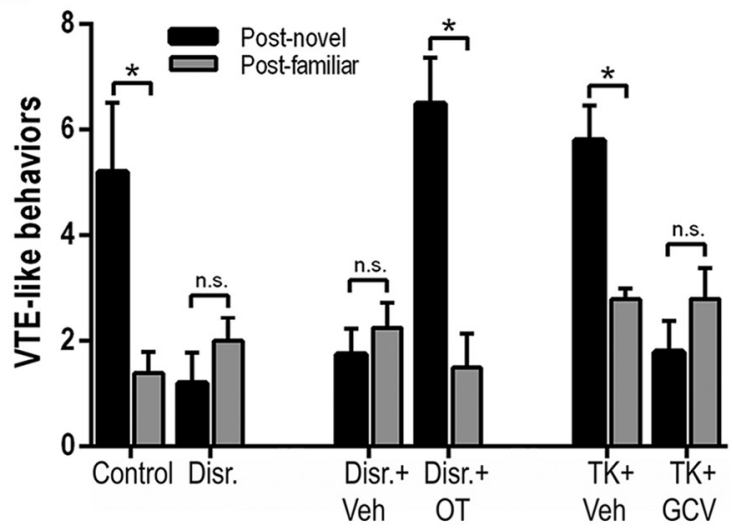

Figure 5. VTE behavior in the social preference test changes in groups with suppressed adult neurogenesis. $A$, Diagram showing VTE-like behavior defined by hesitating and turning back after initiating a movement across the social chamber, as well as a non-VTE-like (straight) trajectory. $\boldsymbol{B}$, After investigation of the novel rat, disrupted VBS rats and GFAP-TK rats exhibited fewer instances of VTE-like behavior, resulting in fewer turns back to the novel side, than controls. Oxytocin treatment reversed the effects of social disruption on VTE-like behavior so that the values were similar to socially naive controls. No significant changes were observed in post-familiar VTE-like behavior in any group. Bars indicate mean post-investigation VTE-like behavior. Error bars indicate SEM. ${ }^{*} p<$ 0.05. Disr., Disruption; n.s., no significant difference; Veh, vehicle.

ruption oxytocin administration may still produce changes in social behavior by acting through other mechanisms (Witt et al., 1992; Lee et al., 2007; Lukas et al., 2011). Additional experiments will be necessary to determine whether oxytocin treatment would produce long-term changes in social behavior if adult neurogenesis levels were kept constant.

Changes in social preference behavior after social disruption could reflect one of the following possibilities: (1) an inability to distinguish novel from familiar conspecifics; (2) a decrease in the natural preference for novelty; or (3) anxiety that causes stressed rats to avoid novel rats. These possibilities seem unlikely, given that socially disrupted rats in our studies showed no impairment in recognizing novel rats, they investigated novel more than familiar rats (and for durations of time that were indistinguishable from controls), and they demonstrated no obvious increase in general anxiety-like behavior. In fact, socially disrupted rats appeared to be less anxious than control rats on the elevated plus maze. The possibility that preference for a familiar, rather than a novel, rat reflects stress-induced social anxiety also seems unlikely because, if this were the case, we would also expect to see less investigation of the novel rat during initial exposure, which was not observed.

A more detailed analysis of behavior in the social apparatus suggested that disrupted rats may have diminished ability to op- 
timize decision making. This possibility is consistent with literature suggesting that the hippocampus participates in resolving conflicts between different goals, particularly when they have similar value, for use in decision-making (Johnson et al., 2007; Bannerman et al., 2012; Doll et al., 2015; Palombo et al., 2015). In our study, after bouts of social investigation, rats either sat without moving to a different location or turned away from the investigated rat and began to traverse the testing apparatus. When control rats turned away after investigating the novel rat, rather than continuing to the other side of the testing apparatus, they often hesitated and turned back toward the novel rat and returned to rest there. In maze training, movements back and forth at difficult choice points have been described as VTE behavior and are considered as a reflection of working memory-dependent deliberative decision-making (Tolman, 1938; Hu et al., 1997; Redish, 2016). This behavior is diminished by lesions to the hippocampus (Hu and Amsel, 1995; Bett et al., 2012). The turning back behavior in our study may also reflect the outcome of a VTE process, in which the rat predicts likely outcomes of different actions. In controls, this VTE-like behavior was displayed to a much lesser extent after investigating the familiar rat, suggesting that its occurrence may reflect a greater difficulty in choosing to leave the more rewarding novel rat. When rats with reduced levels of adult neurogenesis (as a result of social disruption or transgenic inhibition) turned away from the investigated novel rat, they engaged in significantly less turning back to rest by the novel rat; instead, they more frequently continued to traverse the testing apparatus and rested by the familiar rat. This pattern of behavior raises the possibility that new neurons may be involved in choosing between moving back toward the rat that was investigated less recently or returning to the rat that is generally more novel. Because the investigation rate was higher on the novel side for both groups, uninterrupted traversals led the experimental group to rest more frequently near the familiar rat. Some evidence suggests that new neurons can be activated in response to novelty (Sandoval et al., 2011; Clark et al., 2012; Marrone et al., 2012; Meconi et al., 2015) and are important in tasks requiring flexible decision-making (Burghardt et al., 2012; Swan et al., 2014), which has been associated with VTE (Redish, 2016). It may be relevant to note that aging, which is associated with reduced adult neurogenesis (Kuhn et al., 1996; Cameron and McKay, 1999; Heine et al., 2004; McDonald and Wojtowicz, 2005), also results in diminished VTE maze behavior (Breton et al., 2015), suggesting that this may be a mechanism that extends beyond social behavior.

Studies have shown that stress-induced changes in behavior may be adaptive in many circumstances (Lagace et al., 2010; Petrik et al., 2012; Blanchard et al., 2013). In this light, a decrease in novelty preference may signal a "survival-mode" optimization of hippocampal function through stress-induced changes in adult neurogenesis (Glasper et al., 2012). It is also possible that control rats may have an exaggerated focus on novelty given that their housing conditions lack much of the stimulation that is typically present when living in the wild. The possibility that individual housing interacts with the relevance of novelty is also an additional important consideration. Although we housed rats individually after the social disruption to avoid interference of additional social experience, we cannot rule out the possibility that some of our effects resulted from an interaction between social disruption and social isolation. However, because our GFAP-TK rats did not experience social disruption or social isolation at any point in the study, this interpretation seems unlikely.

These findings demonstrate experience-induced change in behavior after experience-induced suppression of adult neurogenesis. Together, these data suggest that suppression in neurogenesis in the DG during adulthood may produce lasting changes in social behavior without causing obvious impairments in hippocampal functions, such as object location memory and anxiety regulation. The lack of effect on object location memory and anxiety-like behavior with reduced adult neurogenesis is consistent with data from naive mice lacking immature neurons (Garrett et al., 2015; Seo et al., 2015). Our results challenge the more established pattern of results wherein negative experiences tend to suppress adult neurogenesis and impair cognitive performance, as well as increase anxiety-like behavior (Leuner and Gould, 2010). Social disruption indeed produces a suppression in adult neurogenesis, but this does not appear to globally impair hippocampal function and instead is associated with a social preference phenotype that may be adaptive rather than pathological. Future work will be necessary to determine the mechanisms underlying social disruption-induced suppression of adult neurogenesis, as well as the long-term consequences of altered social preference behavior.

\section{References}

Albeck DS, McKittrick CR, Blanchard DC, Blanchard RJ, Nikulina J, McEwen BS, Sakai RR (1997) Chronic social stress alters levels of corticotropinreleasing factor and arginine vasopressin mRNA in rat brain. J Neurosci 17:4895-4903. Medline

Alonso R, Griebel G, Pavone G, Stemmelin J, Le Fur G, Soubrié P (2004) Blockade of CRF1 or V1b receptors reverses stress-induced suppression of neurogenesis in a mouse model of depression. Mol Psychiatry 9:278-286, 224. CrossRef Medline

Banasr M, Soumier A, Hery M, Mocaër E, Daszuta A (2006) Agomelatine, a new antidepressant, induces regional changes in hippocampal neurogenesis. Biol Psychiatry 59:1087-1096. CrossRef Medline

Bannerman DM, Bus T, Taylor A, Sanderson DJ, Schwarz I, Jensen V, Hvalby $\varnothing$, Rawlins JN, Seeburg PH, Sprengel R (2012) Dissecting spatial knowledge from spatial choice by hippocampal NMDA receptor deletion. Nat Neurosci 15:1153-1159. CrossRef Medline

Barker GR, Warburton EC (2011) When is the hippocampus involved in recognition memory? J Neurosci 31:10721-10731. CrossRef Medline

Barnett SA (1958) An analysis of social behavior in wild rats. Proc Zool Soc Lond 130:107-152.

Bett D, Allison E, Murdoch LH, Kaefer K, Wood ER, Dudchenko PA (2012) The neural substrates of deliberative decision making: contrasting effects of hippocampus lesions on performance and vicarious trial-and-error behavior in a spatial memory task and a visual discrimination task. Front Behav Neurosci 6:70. CrossRef Medline

Blanchard DC, Cholvanich P, Blanchard RJ, Clow DW, Hammer RP Jr, Rowlett JK, Bardo MT (1991) Serotonin, but not dopamine, metabolites are increased in selected brain regions of subordinate male rats in a colony environment. Brain Res 568:61-66. CrossRef Medline

Blanchard DC, Spencer RL, Weiss SM, Blanchard RJ, McEwen B, Sakai RR (1995) Visible burrow system as a model of chronic social stress: behavioral and neuroendocrine correlates. Psychoneuroendocrinology 20: 117-134. CrossRef Medline

Blanchard DC, Summers CH, Blanchard RJ (2013) The role of behavior in translational models for psychopathology: functionality and dysfunctional behaviors. Neurosci Biobehav Rev 37:1567-1577. CrossRef Medline

Bossarte RM, Blosnich JR, Piegari RI, Hill LL, Kane V (2013) Housing instability and mental distress among US veterans. Am J Public Health 103:S213-S216. CrossRef Medline

Bourke CH, Glasper ER, Neigh GN (2014) SSRI or CRF antagonism partially ameliorate depressive-like behavior after adolescent social defeat. Behav Brain Res 270:295-299. CrossRef Medline

Branchi I, Curley JP, D’Andrea I, Cirulli F, Champagne FA, Alleva E (2013a) Early interactions with mother and peers independently build adult social skills and shape BDNF and oxytocin receptor brain levels. Psychoneuroendocrinology 38:522-532. CrossRef Medline

Branchi I, Santarelli S, D'Andrea I, Alleva E (2013b) Not all stressors are 
equal: early social enrichment favors resilience to social but not physical stress in male mice. Horm Behav 63:503-509. CrossRef Medline

Breton YA, Seeland KD, Redish AD (2015) Aging impairs deliberation and behavioral flexibility in inter-temporal choice. Front Aging Neurosci 7:41. CrossRef Medline

Brudzynski SM (2013) Ethotransmission: communication of emotional states through ultrasonic vocalization in rats. Curr Opin Neurobiol 23: 310-317. CrossRef Medline

Burghardt NS, Park EH, Hen R, Fenton AA (2012) Adult-born hippocampal neurons promote cognitive flexibility in mice. Hippocampus 22: 1795-1808. CrossRef Medline

Cameron HA, McKay RD (1999) Restoring production of hippocampal neurons in old age. Nat Neurosci 2:894-897. CrossRef Medline

Clark PJ, Bhattacharya TK, Miller DS, Kohman RA, DeYoung EK, Rhodes JS (2012) New neurons generated from running are broadly recruited into neuronal activation associated with three different hippocampusinvolved tasks. Hippocampus 22:1860-1867. CrossRef Medline

Crawley JN (2007) Mouse behavioral assays relevant to the symptoms of autism. Brain Pathol 17:448-459. CrossRef Medline

Cutuli JJ, Desjardins CD, Herbers JE, Long JD, Heistad D, Chan CK, Hinz E, Masten AS (2013) Academic achievement trajectories of homeless and highly mobile students: Resilience in the context of chronic and acute risk. Child Dev 84:841-857. CrossRef Medline

Czéh B, Welt T, Fischer AK, Erhardt A, Schmitt W, Müller MB, Toschi N, Fuchs E, Keck ME (2002) Chronic psychosocial stress and concomitant repetitive transcranial magnetic stimulation: effects on stress hormone levels and adult hippocampal neurogenesis. Biol Psychiatry 52:10571065. CrossRef Medline

Daniels WM, de Klerk Uys J, van Vuuren P, Stein DJ (2008) The development of behavioral and endocrine abnormalities in rats after repeated exposure to direct and indirect stress. Neuropsychiatr Dis Treat 4:451464. CrossRef Medline

Deng W, Gage FH (2015) The effect of immature adult-born dentate granule cells on hyponeophagial behavior is related to their roles in learning and memory. Front Syst Neurosci 9:34. CrossRef Medline

Doll BB, Shohamy D, Daw ND (2015) Multiple memory systems as substrates for multiple decision systems. Neurobiol Learn Mem 117:4-13. CrossRef Medline

Dupret D, Revest JM, Koehl M, Ichas F, De Giorgi F, Costet P, Piazza PV (2008) Spatial relational memory requires hippocampal adult neurogenesis. PLoS One 33:e1959. CrossRef Medline

Eagle AL, Fitzpatrick CJ, Perrine SA (2013) Single prolonged stress impairs social and object novelty recognition in rats. Behav Brain Res 256: 591-597. CrossRef Medline

Engelmann M, Wojtak CT, Landgraf R (1995) Social discrimination procedure: an alternative method to investigate juvenile recognition abilities in rats. Physiol Behav 58:315-321. CrossRef Medline

File SE, Aranko K (1988) Sodium valproate and chlordiazepoxide in the elevated plus-maze test of anxiety in the rat. Neuropsychobiology 20: 82-86. CrossRef Medline

Fries E, Hesse J, Hellhammer J, Hellhammer DH (2005) A new view on hypocortisolism. Psychoneuroendocrinology 30:1010-1016. CrossRef Medline

Garrett L, Zhang J, Zimprich A, Niedermeier KM, Fuchs H, GailusDurner V, Hrabě de Angelis M, Vogt Wiesenhorn D, Wurst W, Hölter SM (2015) Conditional reduction of adult born doublecortinpositive neurons reversibly impairs selective behaviors. Front Behav Neurosci 9:302. CrossRef Medline

Gimpl G, Fahrenholz F (2001) The oxytocin receptor system: structure, function, and regulation. Physiol Rev 81:629-683. Medline

Glasper ER, Schoenfeld TJ, Gould E (2012) Adult neurogenesis: optimizing hippocampal function to suit the environment. Behav Brain Res 227: 380-383. CrossRef Medline

Gunnar MR, Talge NM, Herrera A (2009) Stressor paradigms in developmental studies: what does and does not work to produce mean increases in salivary cortisol. Psychoneuroendocrinology 34:953-967. CrossRef Medline

Heine VM, Maslam S, Joëls M, Lucassen PJ (2004) Prominent decline of newborn cell proliferation, differentiation, and apoptosis in the aging dentate gyrus, in absence of an age-related hypothalamus-pituitary-adrenal axis activation. Neurobiol Aging 25:361-375. CrossRef Medline

Hu D, Amsel A (1995) A simple test of the vicarious trial-and-error hypoth- esis of hippocampal function. Proc Natl Acad Sci U S A 92:5506-5509. CrossRef Medline

Hu D, Griesbach G, Amsel A (1997) Development of vicarious trial-anderror behavior in odor discrimination learning in the rat: relation to hippocampal function? Behav Brain Res 86:67-70. CrossRef Medline

Johnson A, van der Meer MA, Redish AD (2007) Integrating hippocampus and striatum in decision-making. Curr Opin Neurobiol 17:692-697. CrossRef Medline

Kempermann G, Gast D, Kronenberg G, Yamaguchi M, Gage FH (2003) Early determination and long-term persistence of adult-generated new neurons in the hippocampus of mice. Development 130:391-399. CrossRef Medline

Khoshaba DM, Maddi SR (1999) Early experiences in hardiness development. Consult Psychol J Prac Res 51:106. CrossRef

Koolhaas JM, de Boer SF, Coppens CM, Buwalda B (2010) Neuroendocrinology of coping styles: towards understanding the biology of individual variation. Front Neuroendocrinol 31:307-321. CrossRef Medline

Korte SM, Meijer OC, de Kloet ER, Buwalda B, Keijser J, Sluyter F, van Oortmerssen G, Bohus B (1996) Enhanced 5-HT 1A receptor expression in forebrain regions of aggressive house mice. Brain Res 736:338343. CrossRef Medline

Kozorovitskiy Y, Gould E (2004) Dominance hierarchy influences adult neurogenesis in the dentate gyrus. J Neurosci 24:6755-6759. CrossRef Medline

Krames L, Carr WJ, Bergman B (1969) A pheromone associated with social dominance among male rats. Psychonom Sci 16:11-12. CrossRef

Kremarik P, Freund-Mercier MJ, Stoeckel ME (1995) Oxytocin and vasopressin binding sites in the hypothalamus of the rat: histoautoradiographic detection. Brain Res Bull 36:195-203. CrossRef Medline

Kuhn HG, Dickinson-Anson H, Gage FH (1996) Neurogenesis in the dentate gyrus of the adult rat: age-related decrease of neuronal progenitor proliferation. J Neurosci 16:2027-2033. Medline

Lagace DC, Donovan MH, DeCarolis NA, Farnbauch LA, Malhotra S, Berton O, Nestler EJ, Krishnan V, Eisch AJ (2010) Adult hippocampal neurogenesis is functionally important for stress-induced social avoidance. Proc Natl Acad Sci U S A 107:4436-4441. CrossRef Medline

Lee PR, Brady DL, Shapiro RA, Dorsa DM, Koenig JI (2007) Prenatal stress generates deficits in rat social behavior: reversal by oxytocin. Brain Res 1156:152-167. CrossRef Medline

Leuner B, Gould E (2010) Structural plasticity and hippocampal function. Annu Rev Psychol 61:111-140, C1-C3. CrossRef Medline

Leuner B, Glasper ER, Gould E (2009) Thymidine analog methods for studies of adult neurogenesis are not equally sensitive. J Comp Neurol 517: 123-133. CrossRef Medline

Leuner B, Caponiti JM, Gould E (2012) Oxytocin stimulates adult neurogenesis even under conditions of stress and elevated glucocorticoids. Hippocampus 22:861-868. CrossRef Medline

Liberzon I, Young EA (1997) Effects of stress and glucocorticoids on CNS oxytocin receptor binding. Psychoneuroendocrinology 22:411-422. CrossRef Medline

Lister RG (1987) The use of a plus-maze to measure anxiety in the mouse. Psychopharmacology 92:180-185. Medline

Lugert S, Basak O, Knuckles P, Haussler U, Fabel K, Götz M, Haas CA, Kempermann G, Taylor V, Giachino C (2010) Quiescent and active hippocampal neural stem cells with distinct morphologies respond selectively to physiological and pathological stimuli and aging. Cell Stem Cell 6:445-456. CrossRef Medline

Lukas M, Toth I, Reber SO, Slattery DA, Veenema AH, Neumann ID (2011) The neuropeptide oxytocin facilitates pro-social behavior and prevents social avoidance in rats and mice. Neuropsychopharmacology 36: 2159-2168. CrossRef Medline

Mak GK, Weiss S (2010) Paternal recognition of adult offspring mediated by newly generated CNS neurons. Nat Neurosci 13:753-758. CrossRef Medline

Marrone DF, Ramirez-Amaya V, Barnes CA (2012) Neurons generated in senescence maintain capacity for functional integration. Hippocampus 22:1134-1142. CrossRef Medline

McCormick CM, Green MR (2013) From the stressed adolescent to the anxious and depressed adult: investigations in rodent models. Neuroscience 249:242-257. CrossRef Medline

McCormick CM, Thomas CM, Sheridan CS, Nixon F, Flynn JA, Mathews IZ (2012) Social instability stress in adolescent male rats alters hippocampal 
neurogenesis and produces deficits in spatial location memory in adulthood. Hippocampus 22:1300-1312. CrossRef Medline

McCormick CM, Hodges TE, Simone JJ (2015) Peer pressures: social instability stress in adolescence and social deficits in a rodent model. Dev Cogn Neurosci 11:2-11. CrossRef Medline

McDonald HY, Wojtowicz JM (2005) Dynamics of neurogenesis in the dentate gyrus of adult rats. Neurosci Lett 385:70-75. CrossRef Medline

McEwen BS (1998) Stress, adaptation, and disease: allostasis and allostatic load. Ann NY Acad Sci 840:33-44. CrossRef Medline

McHugh SB, Deacon RM, Rawlins JN, Bannerman DM (2004) Amygdala and ventral hippocampus contribute differentially to mechanisms of fear and anxiety. Behav Neurosci 118:63-78. CrossRef Medline

Meconi A, Lui E, Marrone DF (2015) Sustained Arc expression in adultgenerated granule cells. Neurosci Lett 603:66-70. CrossRef Medline

Morris AM, Weeden CS, Churchwell JC, Kesner RP (2013) The role of the dentate gyrus in the formation of contextual representations. Hippocampus 23:162-168. CrossRef Medline

Moy SS, Nadler JJ, Perez A, Barbaro RP, Johns JM, Magnuson TR, Piven J, Crawley JN (2004) Sociability and preference for social novelty in five inbred strains: an approach to assess autistic-like behavior in mice. Genes Brain Behav 3:287-302. CrossRef Medline

Opendak M, Gould E (2015) Adult neurogenesis: a substrate for experiencedependent change. Trends Cogn Sci 19:151-161. CrossRef Medline

Palombo DJ, Keane MM, Verfaellie M (2015) How does the hippocampus shape decisions? Neurobiol Learn Mem 125:93-97. CrossRef Medline

Pellow S, File SE (1986) Anxiolytic and anxiogenic drug effects on exploratory activity in an elevated plus maze: a novel test of anxiety in the rat. Pharmacol Biochem Behav 24:525-529. CrossRef Medline

Petrik D, Lagace DC, Eisch AJ (2012) The neurogenesis hypothesis of affective and anxiety disorders: are we mistaking the scaffolding for the building? Neuropharmacology 62:21-34. CrossRef Medline

Popik P, Vetulani J, van Ree JM (1992) Low doses of oxytocin facilitate social recognition in rats. Psychopharmacology 106:71-74. CrossRef Medline

Redish AD (2016) Vicarious trial and error. Nat Rev Neurosci 17:147-159. CrossRef Medline

Rohleder N, Joksimovic L, Wolf JM, Kirschbaum C (2004) Hypocortisolism and increased glucocorticoid sensitivity of pro-Inflammatory cytokine production in Bosnian war refugees with posttraumatic stress disorder. Biol Psychiatry 55:745-751. CrossRef Medline

Sandoval CJ, Martínez-Claros M, Bello-Medina PC, Pérez O, RamírezAmaya V (2011) When are new hippocampal neurons, born in the adult brain, integrated into the network that processes spatial information? PLoS One 6:e17689. CrossRef Medline

Schoenfeld TJ, Kloth AD, Hsueh B, Runkle MB, Kane GA, Wang SS, Gould E (2014) Gap junctions in the ventral hippocampal-medial prefrontal pathway are involved in anxiety regulation. J Neurosci 34:15679-15688. CrossRef Medline

Seo DO, Carillo MA, Chih-Hsiung Lim S, Tanaka KF, Drew MR (2015) Adult hippocampal neurogenesis modulates fear learning through associative and nonassociative mechanisms. J Neurosci 35:11330-11345. CrossRef Medline

Siegel SJ, Ginsberg SD, Hof PR, Foote SL, Young WG, Kraemer GW, McKinney WT, Morrison JH (1993) Effects of social deprivation in prepubescent rhesus monkeys: immunohistochemical analysis of the neurofilament protein triplet in the hippocampal formation. Brain Res 619:299-305. CrossRef Medline

Snyder JS, Choe JS, Clifford MA, Jeurling SI, Hurley P, Brown A, Kamhi JF,
Cameron HA (2009) Adult-born hippocampal neurons are more numerous, faster maturing, and more involved in behavior in rats than in mice. J Neurosci 29:14484-14495. CrossRef Medline

Snyder JS, Soumier A, Brewer M, Pickel J, Cameron HA (2011) Adult hippocampal neurogenesis buffers stress responses and depressive behavior. Nature 476:458-461. CrossRef Medline

Snyder JS, Grigereit L, Russo A, Seib D, Brewer M, Pickel J, Cameron HA (2016) A transgenic rat for specifically inhibiting adult neurogenesis. eNeuro doi: 10.1523/ENEURO.0064-16.2016.

Staples LG, Cornish JL (2014) The orexin-1 receptor antagonist SB-334867 attenuates anxiety in rats exposed to cat odor but not the elevated plus maze: an investigation of Trial 1 and Trial 2 effects. Horm Behav 65: 294-300. CrossRef Medline

Suh H, Consiglio A, Ray J, Sawai T, D’Amour KA, Gage FH (2007) In vivo fate analysis reveals the multipotent and self-renewal capacities of Sox $2+$ neural stem cells in the adult hippocampus. Cell Stem Cell 1:515-528. CrossRef Medline

Sun H, Jia N, Guan L, Su Q, Wang D, Li H, Zhu Z (2013) Involvement of NR1, NR2A different expression in brain regions in anxiety-like behavior of prenatally stressed offspring. Behav Brain Res 257:1-7. CrossRef Medline

Swan AA, Clutton JE, Chary PK, Cook SG, Liu GG, Drew MR (2014) Characterization of the role of adult neurogenesis in touch-screen discrimination learning. Hippocampus 24:1581-1591. CrossRef Medline

Thor DH, Holloway WR (1982) Social memory of the male laboratory rat. J Comp Physiol Psychol 96:1000. CrossRef

Tolman EC (1938) The determiners of behavior at a choice point. Psychol Rev 45:1-41. CrossRef

Tribollet E, Barberis C, Jard S, Dubois-Dauphin M, Dreifuss JJ (1988) Localization and pharmacological characterization of high affinity binding sites for vasopressin and oxytocin in the rat brain by light microscopic autoradiography. Brain Res 442:105-118. CrossRef Medline

Tsai CY, Tsai CY, Arnold SJ, Huang GJ (2015) Ablation of hippocampal neurogenesis in mice impairs the response to stress during the dark cycle. Nat Commun 6:8373. CrossRef Medline

van der Kooij MA, Sandi C (2012) Social memories in rodents: methods, mechanisms and modulation by stress. Neurosci Biobehav Rev 36: 1763-1772. CrossRef Medline

Veenema AH, Neumann ID (2007) Neurobiological mechanisms of aggression and stress coping: a comparative study in mouse and rat selection lines. Brain Behav Evol 70:274-285. CrossRef Medline

Vega CJ, Peterson DA (2005) Stem cell proliferative history in tissue revealed by temporal halogenated thymidine analog discrimination. Nat Methods 2:167-169. CrossRef Medline

Vives A, Vanroelen C, Amable M, Ferrer M, Moncada S, Llorens C, Muntaner C, Benavides FG, Benach J (2011) Employment precariousness in Spain: prevalence, social distribution, and population-attributable risk percent of poor mental health. Int J Health Serv 41:625-646. CrossRef Medline

Walf AA, Frye CA (2007) The use of the elevated plus maze as an assay of anxiety-related behavior in rodents. Nat Protocols 2:322-328. CrossRef Medline

Witt DM, Winslow JT, Insel TR (1992) Enhanced social interactions in rats following chronic, centrally infused oxytocin. Pharmacol Biochem Behav 43:855-861. CrossRef Medline

Yehuda R, Southwick SM, Nussbaum G, Wahby V, Giller Jr EL, Mason JW (1990) Low urinary cortisol excretion in patients with posttraumatic stress disorder. J Nerv Ment Dis 178:366-369. CrossRef Medline 